\title{
Thymidylate Synthase as a Prognostic Biomarker for Locally Advanced Rectal Cancer after multimodal Treatment
}

\author{
Lena-Christin Conradi ${ }^{1}$, Annalen Bleckmann ${ }^{2,3}$, Markus Schirmer ${ }^{5}$, Thilo Sprenger ${ }^{1}$, Peter Jo ${ }^{1}$, Kia Homayounfar ${ }^{1}$, \\ Hendrik A. Wolff ${ }^{6}$, Hilka Rothe ${ }^{4}$, Peter Middel ${ }^{4}$, Heinz Becker ${ }^{1}$, Michael B. Ghadimi ${ }^{1}$, Tim Beissbarth ${ }^{2}$, and \\ Torsten Liersch ${ }^{1}$ \\ ${ }^{1}$ Department of General and Visceral Surgery Department of General and Visceral Surgery, Göttingen University Medical \\ Center, Göttingen, Germany; ${ }^{2}$ Department of Medical Statistics, University Medical Center, Göttingen, Germany; \\ ${ }^{3}$ Department of Hematology and Oncology, University Medical Center, Göttingen, Germany; ${ }^{4}$ Institute for Pathology, \\ University Medical Center, Göttingen, Germany; ${ }^{5}$ Department of Clinical Pharmacology, University Medical Center, \\ Göttingen, Germany; ${ }^{6}$ Department of Radiooncology, University Medical Center, Göttingen, Germany
}

\begin{abstract}
Purpose. For years, 5-fluorouracil (5-FU) has been the backbone of radiochemotherapy (RCT) of locally advanced rectal cancer. Its main target, thymidylate synthase (TS), is speculated to be an important biomarker for response prediction and long-term prognosis. In this study, we analyzed TS expression in the rectal cancer tissue of 208 patients to evaluate its predictive/prognostic potential.

Methods. All patients included were diagnosed with locally advanced adenocarcinoma of the rectum (UICC II and III) and were treated within randomized clinical trials of the German Rectal Cancer Study Group. Preoperative RCT (50.4 Gy and concomitant either 5-FU or 5-FU and oxaliplatin) was administered in 167 patients followed by surgical resection with total mesorectal excision (TME). Another 41 patients received postoperative RCT. TS levels and further clinicopathological parameters were assessed in
\end{abstract}

This work was supported by the Deutsche Forschungsgemeinschaft (KFO 179).

Electronic supplementary material The online version of this article (doi:10.1245/s10434-011-1608-4) contains supplementary material, which is available to authorized users.

(C) The Author(s) 2011. This article is published with open access at Springerlink.com

First Received: 29 November 2010;

Published Online: 23 February 2011

L.-C. Conradi

e-mail: lena.conradi@med.uni-goettingen.de

T. Liersch

e-mail: tliersc@gwdg.de univariate and multivariate analyses. Additionally, a TS gene polymorphism was analyzed with respect to the intratumoral protein levels.

Results. Low TS expression in pretreatment biopsies correlated with impaired patient survival $(p=0.015)$. Analysis of a 28 -bp repeat revealed a correlation between the $* 3 / * 3$ genotype and high TS expression in pretherapeutic biopsies. In this study, a correlation of TS expression and grade of RCT-induced tumor regression was not found. Histopathological examination confirmed a complete tumor remission in 16 patients $(9.6 \%)$.

Analyses of the resection specimen indicated an unfavorable prognosis for patients with low intratumoral TS expression in case of detected lymph node metastases $(p=0.04)$.

Conclusions. TS can serve as a prognostic biomarker indicating an unfavorable prognosis for patients with low TS expression.

During the past two decades, preoperative multimodal strategies and optimized surgical procedures, including total mesorectal excision (TME), have been increasingly used to treat UICC (Union International Contre le Cancer) stage II and III rectal cancer. ${ }^{1-3}$ In particular, several studies have demonstrated that neoadjuvant 5-fluorouracil (5-FU)based radiochemotherapy (RCT) significantly improves locoregional control, as well as sphincter preservation and the toxicity profile, compared with postoperative $\mathrm{RCT}^{4-7}$ Therefore, neoadjuvant RCT is recommended as the standard treatment for locally advanced rectal cancer. ${ }^{8}$ Although RCT-induced complete tumor regression, T-level 
downsizing and UICC downstaging are important surrogate parameters, no reliable biomarkers for individual prognosis and response prediction to neoadjuvant RCT have yet been established. ${ }^{6,9-12}$

With a 5-year distant relapse rate of $30-40 \%$, the occurrence of systemic metastatic spread remains the predominant mode of failure and limits long-term prognosis. ${ }^{7,13}$ From the clinical point of view, the implementation of more risk-adapted therapy approaches is required. This notion applies to both the neoadjuvant part of multimodal treatment and the adjuvant situation because evidence on adjuvant chemotherapy (CT) is controversially discussed. ${ }^{14,15}$ Currently, ongoing clinical trials, such as the CAO/ARO/ AIO-04 trial [EudraCT-No: 2006-002385] ${ }^{16}$, are testing intensified neoadjuvant RCT for improving local complete response (pCR) and adjuvant $\mathrm{CT}$ to increase overall cancerspecific survival (CSS). Nevertheless, the approved antimetabolite and radiosensitizer 5-FU remains the backbone of systemic therapy. ${ }^{17,18}$

In 5-FU metabolism, thymidylate synthase (TS) is the central molecular target; TS is essential for de novo DNA synthesis. ${ }^{19}$ A specific connection between TS expression and tumor cell viability was previously shown. ${ }^{20}$ In several small-sized studies, the potential of TS as a valid biomarker has been investigated in multimodal treatment regimens; however, no final conclusion about its predictive and/or prognostic value has been gained. ${ }^{21-23}$

Previous studies suggest that pretherapeutic TS expression may predict individual response to neoadjuvant 5-FUbased RCT in rectal cancer. ${ }^{24-26}$ Additionally, the TS level in residual tumor specimens after RCT may be of prognostic value and allow stratification of patients with different risk profiles for recurrence. The purpose of this study was to evaluate the potential of TS as a predictive and prognostic biomarker in patients with rectal cancer, who were treated with standard preoperative 5-FU or 5-FU/ oxaliplatin protocols. TS protein levels were evaluated by immunohistochemical (IHC) staining of pretherapeutic biopsies and residual tumors after surgery. A tandem repeat polymorphism within the TS gene, which has been repeatedly discussed for the efficacy of 5-FU-based chemotherapy, was identified in the germline DNA extracted from the peripheral blood cells of these patients. ${ }^{27}$

\section{PATIENTS AND METHODS}

\section{Eligibility and Clinical Assessments}

Patients (mean age, $62.6 \pm 9.5$ years; 145 men and 63 women) with primary rectal cancer received 5-FU-based RCT within randomized clinical phase-II/-III-trials of the German Rectal Cancer Study Group (CAO/ARO/AIO-04,
XelOX-trial, CAO/ARO/AIO-94). One hundred sixtyseven $(80.3 \%)$ patients received neoadjuvantly 5-FU $(\mathrm{n}=103)$ or $5-\mathrm{FU}$ and oxaliplatin $(n=64)$ (Fig. 1). Forty-one $(19.7 \%)$ patients were conveyed to primary surgery, followed by adjuvant 5-FU RCT. All patients were treated at the Department of General and Visceral Surgery, University Medical Center Göttingen (Göttingen, Germany), between 1998 and 2009. Eligibility criteria included histologically confirmed adenocarcinoma, located no more than $16 \mathrm{~cm}$ above the anocutaneous verge, as measured by rigid rectoscopy, a complete medical history, physical examination, peripheral blood cell count, chest $\mathrm{x}$-ray, abdominal ultrasound, and carcinoembryonic anti-

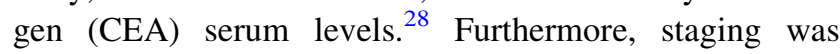
completed by endorectal ultrasound (EUS) and contrastenhanced magnetic resonance imaging (MRI) of the pelvis to confirm locally advanced but resectable rectal cancer. Contrast-enhanced computed tomographic (CT) scans of the chest, abdomen, and pelvis were performed to identify patients with distant metastatic disease. At the time of staging, all patients had an Eastern Cooperative Oncology Group (ECOG) performance status of $\leq 2$. $^{29}$ The study was approved by the medical ethics committee of the University of Göttingen.

\section{Multimodal Treatment: Radiochemotherapy and Surgery}

Preoperative radiotherapy with a total dose of 50.4 Gy was delivered in 28 fractions of $1.8 \mathrm{~Gy}$ in three-dimensional conformal irradiation by a three-field box technique with 20-MV photons. $^{30,31}$ In 103 patients, 5-FU was scheduled as a 120 - $\mathrm{h}$ infusion of $1,000 \mathrm{mg} / \mathrm{m}^{2}$ per day during weeks 1 and 5. The same RCT regimen was applied postoperatively to the 41 patients receiving adjuvant RCT (Fig. 1). In 64 patients who were randomized to an intensified protocol, neoadjuvant RCT was applied as a combination of 5-FU $\left(250 \mathrm{mg} / \mathrm{m}^{2} / \mathrm{d}\right)$ days $1-14$ and $22-35$ and oxaliplatin $\left(50 \mathrm{mg} / \mathrm{m}^{2} / \mathrm{d}\right)$ days $1,8,22$, and 29 . Six weeks after the completion of neoadjuvant RCT, curative surgery with TME was performed. ${ }^{9}$

Four to six weeks after surgery, multimodal therapy was completed with four cycles of 5 -FU $\left(500 \mathrm{mg} / \mathrm{m}^{2} / \mathrm{d}\right)$ bolus infusion (days 1 to 5) or with eight cycles of 5-FU (2,400 mg/ $\left.\mathrm{m}^{2}\right)$ continuous infusion with folinic acid $\left(400 \mathrm{mg} / \mathrm{m}^{2}\right)$ and oxaliplatin $\left(100 \mathrm{mg} / \mathrm{m}^{2}\right)$ bolus infusion (Fig. 1).

\section{Histopathological Staging and Tumor Regression Grading}

Complete pathological staging included ypTNM stage according to the current TNM classification; the evaluation of longitudinal and circumferential resection margins with 
FIG. 1 Study design. EUS endorectal ultrasound; $C T$ computed tomography; $M R I$ magnetic resonance imaging; $C E A$ carcinoembryonic antigen; $R C T$ radiochemotherapy; 5-FU 5-fluorouracil; ox oxaliplatin; $T M E$ total mesorectal excision; APE abdominoperineal extirpation; $C T x$ chemotherapy; IHC immunohistochemical staining

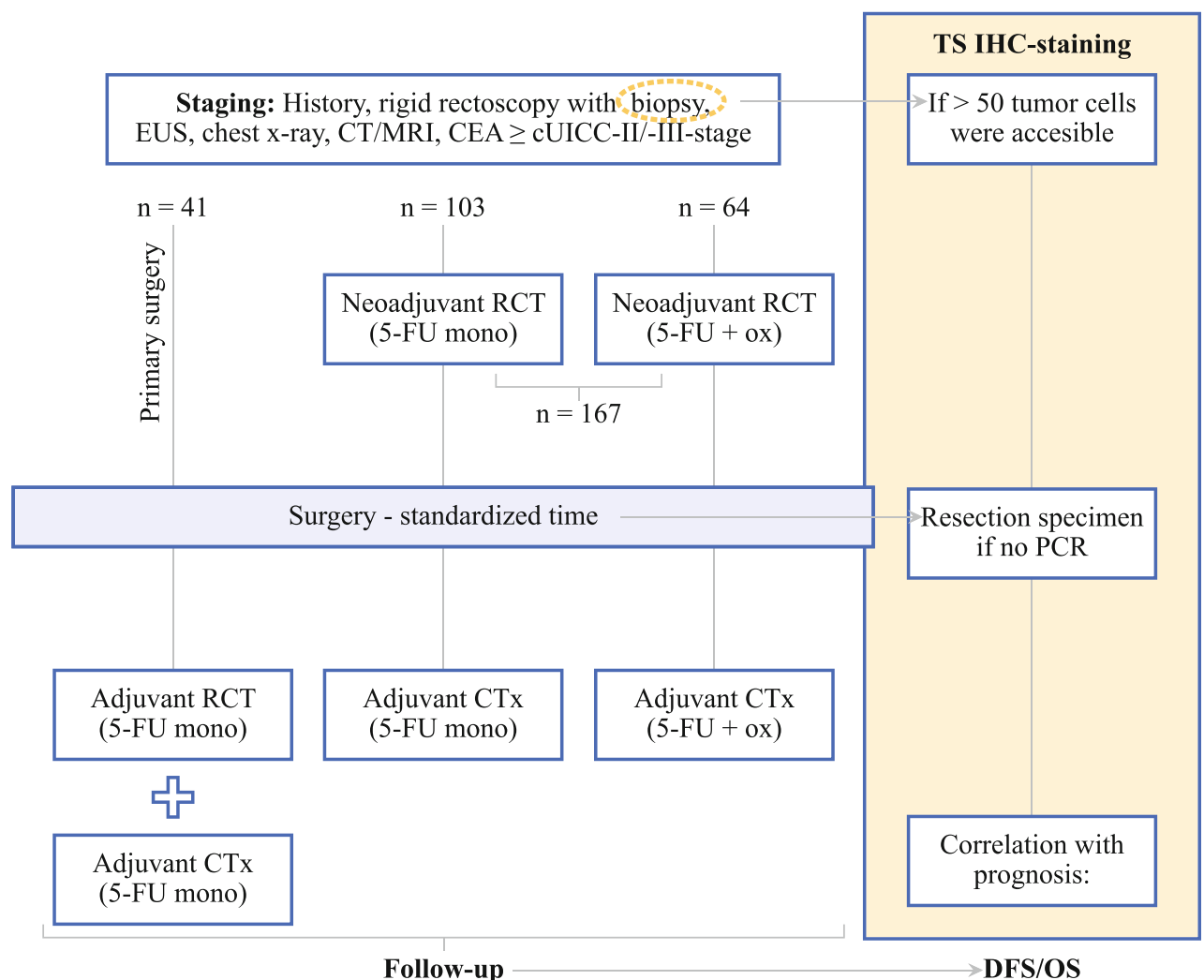

Follow-up

encouraged. Alternate acceptable criteria included specific imaging findings with concurrent elevation of CEA serum levels. CSS was defined as the interval between surgical resection and cancer-related death. Follow-up examinations were performed at 3-month intervals within the first 2 years and at 6-month intervals after 2 years. ${ }^{8}$

\section{Tissue Samples and Immunohistochemical Evaluation} of TS Expression

Tumor specimens were collected at the time of the first biopsy procedure and at the time of surgery (Fig. 1). The TS protein level was assessed on paraffin-embedded, matched tissue samples from pretreatment tumor biopsies and surgical specimens from the same patients. A standardized immunohistochemical staining technique was performed using a Ventana BenchMark XT immunostainer (Ventana, Tucson, AZ) with a mouse anti-human monoclonal antibody to TS (anti-human TS [Rabbit] Code: 100-401-199 Rockland, PA) at a dilution of 1:100. Heat epitope retrieval using the immunostainer was performed for $60 \mathrm{~min}$ at $100^{\circ} \mathrm{C}$. The anti-TS antibody was incubated at $37^{\circ} \mathrm{C}$ for $28 \mathrm{~min}$. The enzymatic reactivity was visualized with alkaline phosphatase (Red Detection Kit, Roche Ventana, Mannheim, Germany).

The immunohistochemical slides were independently evaluated and interpreted by two different observers in a blinded manner, without the knowledge of the clinical and rence. Histologic confirmation of cancer recurrence was
During treatment, all patients were monitored on a weekly basis. Long-term follow-up included rectoscopy, abdominal ultrasound, computed tomography of the abdomelvis, as well as chest X-ray at regular intervals according to the study protocols. Disease-free survival (DFS) was defined as the interval between surgical resection and any evidence of local or systemic cancer recur- 


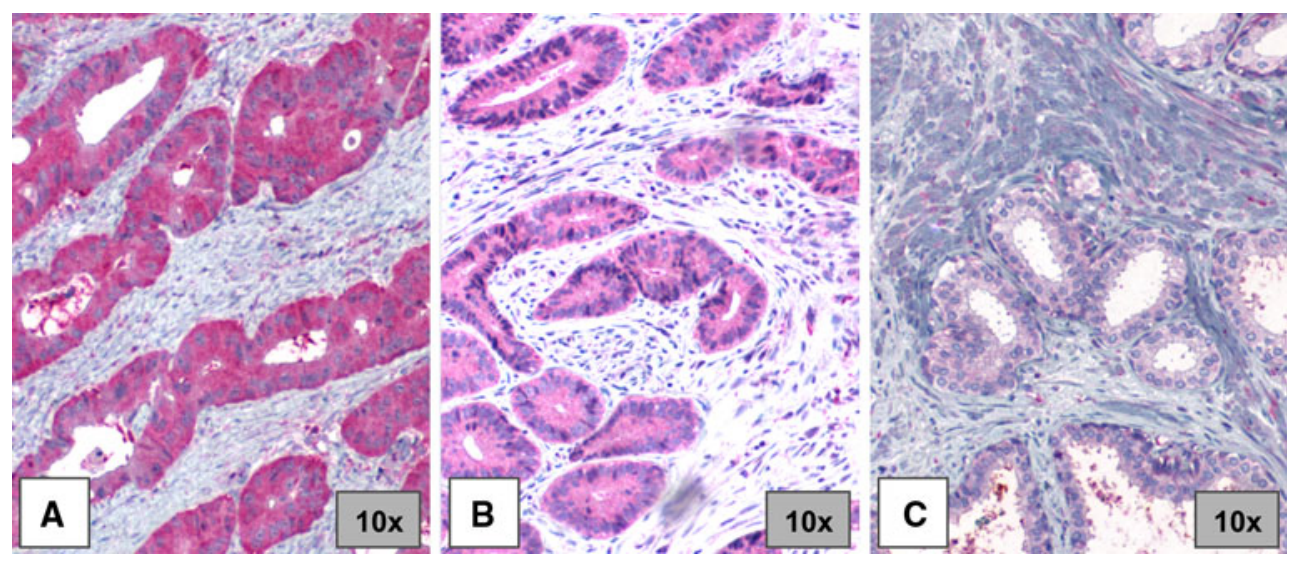

FIG. 2 Examples of TS immunohistochemical staining of human rectal adenocarcinoma cells. a Strong staining intensity in rectal cancer cells. b Cancer cells with a moderate staining pattern. c Negative tumor cells for TS staining

follow-up data. TS immunoreactivity was scored for staining intensity (Fig. 2) and proportion of positive cells when at least 50 tumor cells were accessible. The slides were screened at a low power for pattern and distribution of staining; a higher magnification $(\times 40)$ was used to determine the staining intensity. To record antibody expression, the scoring method by Remmele and Stegner ${ }^{39}$ was adopted and slightly modified to incorporate heterogeneous staining intensities and to obtain a more accurate score. Staining was semiquantitatively evaluated as follows: staining intensity was scored as none (0), weak (1), moderate (2), and strong (3). The tumor cell percentage of each of these four intensity classes was documented (as $\rho_{0}, \rho_{1}$, $\rho_{2}$, and $\rho_{3}$, respectively). The tumor percentage $(\tau)$ was defined as the total percentage of positive tumor cells $\left(\rho_{1}+\rho_{2}+\rho_{3}\right)$. The tumor cell percentage was categorized into five groups: $0=0 \% ; 1=(0-25 \%) ; 2=$ $(25-50 \%) ; 3=(50-75 \%) ; 4=(75-100 \%)$, as the tumor percentage score. The weighted mean of the staining scores weighted by the observed percentages $\left(1\left(\rho_{1} / \tau\right)+\right.$ $\left.2\left(\rho_{2} / \tau\right)+3\left(\rho_{3} / \tau\right)\right) / 3$ was calculated and defined as the tumor staining intensity score. For further statistical analysis, the tumor staining intensity score (range 0-3) and the tumor percentage score (range 0-4) were multiplied to obtain the final TS score (range 0-12). In Kaplan-Meier analyses, low TS expression was defined as a TS score $<7$ and high expression as $T S$ scores $\geq 7$, according to the observed median. Likewise, the cutoff score applied for analyses of pretherapeutic biopsies was set to 4 , in accordance with the median.

\section{Genotyping of TS 28-bp Tandem Repeats}

In the TS gene, the number of the TS 28-bp repeat polymorphism (abbreviated as 28R, rs34743033 according to the dbSNP database: http://www.ncbi.nlm.nih.gov/snp) was genotyped in lymphocytes by fragment length analysis. At first, the genomic fragment containing this repeat was amplified by conventional PCR using Taq polymerase with Q-solution (Qiagen, Hilden, Germany) with FAM labeling of one primer at the $5^{\prime}$ end. PCR conditions were 35 cycles, each consisting of a 50 -s denaturation at $95^{\circ} \mathrm{C}$, a 30 -s annealing at $68.5^{\circ} \mathrm{C}$, and a 60 -s elongation at $72^{\circ} \mathrm{C}$. Primer sequences (each in $5^{\prime}$ to $3^{\prime}$ direction) were GTGGCTCCTGCGTTTCCCC and FAM-TCCGAGCCG GCCACAGGCAT, yielding the fragments of $212 \mathrm{bp}$ (in case of two $28 \mathrm{R}$ repeats, denoted as $28 \mathrm{R} * 2$ ), $240 \mathrm{bp}$ (three $28 \mathrm{R}$ repeats, $28 \mathrm{R} * 3$ ), and, as found only once, $268 \mathrm{bp}$ (four $28 \mathrm{R}$ repeats, $28 \mathrm{R} * 4){ }^{40}$ The fragments with the FAMlabeled primer were analyzed on a sequencing machine (3100 Genetic Analyzer, Applied Biosystems, Foster City, CA). Genescan 400HD (Applied Biosystems) was used as the size standard to allocate fragment length. Determined genotypes were in Hardy-Weinberg equilibrium, as assessed by $\chi^{2}$ test $(p=0.8)$.

\section{Statistical Analysis}

Correlation analysis of the TS score with clinical outcome variables was assessed using the Spearman correlation coefficient and was tested for statistical significance. The impact of the TS score on DFS and CSS was statistically tested using Cox proportional-hazards regression models. For graphical display, the TS score was categorized as low or high and was expressed as a Kaplan-Meier plot. The comparative analysis of patients' clinicopathological characteristics between different groups was performed using a $\chi^{2}$ test. To confirm the prognostic value of further clinicopathologic parameters, these factors were tested in a multivariate model. Additionally, the impact on the following variables that were available at the time of staging (gender, age, uN, 
TABLE 1 Clinical parameters and histopathologic characteristics of examined patient cohorts

\begin{tabular}{|c|c|c|c|c|c|c|c|}
\hline \multirow{2}{*}{$\begin{array}{l}\text { Therapy regimen } \\
\text { Parameter }\end{array}$} & \multicolumn{2}{|c|}{ No neoadjuvant RCT } & \multicolumn{2}{|c|}{$\begin{array}{l}\text { Neoadjuvant RCT with } \\
\text { standard 5-FU }\end{array}$} & \multicolumn{2}{|c|}{$\begin{array}{l}\text { Neoadjuvant RCT with } \\
\text { 5-FU/oxaliplatin }\end{array}$} & \multirow[t]{2}{*}{$p^{*}$} \\
\hline & $\begin{array}{l}\text { No. of patients } \\
(n=41)\end{array}$ & $\%$ & $\begin{array}{l}\text { No. of patients } \\
(n=103)\end{array}$ & $\%$ & $\begin{array}{l}\text { No. of patients } \\
(n=64)\end{array}$ & $\%$ & \\
\hline Age $(y r)$ & & & & & & & 0.85 \\
\hline Mean & 63.3 & & 62.9 & & 61.8 & & \\
\hline Range & $39-75$ & & $35-81$ & & $36-81$ & & \\
\hline Gender & & & & & & & 0.6 \\
\hline Male & 28 & 68 & 75 & 73 & 42 & 66 & \\
\hline Female & 13 & 32 & 28 & 27 & 22 & 34 & \\
\hline Tumor distance from anal verge $(\mathrm{cm})$ & & & & & & & 0.02 \\
\hline $0-6$ & 12 & 29 & 39 & 38 & 31 & 48 & \\
\hline$>6-12$ & 25 & 54 & 59 & 57 & 31 & 48 & \\
\hline$>12-16$ & 7 & 17 & 5 & 5 & 2 & 3 & \\
\hline cT stage & & & & & & & 0.06 \\
\hline 2 & 6 & 15 & 3 & 3 & 2 & 3 & \\
\hline 3 & 33 & 80 & 92 & 89 & 59 & 92 & \\
\hline 4 & 2 & 5 & 8 & 8 & 3 & 5 & \\
\hline $\mathrm{cN}$ stage & & & & & & & 0.11 \\
\hline Positive & 25 & 61 & 73 & 71 & 51 & 80 & \\
\hline Negative & 15 & 39 & 30 & 29 & 13 & 20 & \\
\hline cUICC stage & & & & & & & 0.23 \\
\hline II & 14 & 34 & 31 & 30 & 13 & 20 & \\
\hline III & 27 & 66 & 72 & 70 & 51 & 80 & \\
\hline Surgical procedure ${ }^{\#}$ & & & & & & & 0.35 \\
\hline Low anterior resection & 31 & 76 & 64 & 62 & 48 & 75 & \\
\hline Abdominoperineal resection & 9 & 22 & 37 & 36 & 15 & 23 & \\
\hline Hartmann's procedure & 1 & 2 & 2 & 2 & 1 & 2 & \\
\hline \multicolumn{8}{|l|}{ Postoperative parameters } \\
\hline \multicolumn{8}{|l|}{ Resection status (including CRM) } \\
\hline R0 & 41 & 100 & 103 & 100 & 64 & 100 & \\
\hline $\mathrm{R} 1$ & 0 & 0 & 0 & 0 & 0 & 0 & \\
\hline $\mathrm{R} 2$ & 0 & 0 & 0 & 0 & 0 & 0 & \\
\hline Tumor regression grading & & & & & & & 0.33 \\
\hline 0 No regression & - & - & 0 & 0 & 0 & 0 & \\
\hline 1 Minor regression $(<25 \%)$ & - & - & 14 & 14 & 6 & 9 & \\
\hline 2 Moderate regression $(<50 \%)$ & - & - & 26 & 25 & 10 & 16 & \\
\hline 3 Good regression $(<80 \%)$ & - & - & 54 & 52 & 41 & 64 & \\
\hline 4 Total regression $(100 \%)$ & - & - & 9 & 9 & 7 & 11 & \\
\hline (y)pT stage & & & & & & & 0.1 \\
\hline 0 & 0 & 0 & 9 & 9 & 9 & 14 & \\
\hline 1 & 1 & 2 & 8 & 8 & 9 & 14 & \\
\hline 2 & 9 & 22 & 25 & 24 & 14 & 22 & \\
\hline 3 & 29 & 71 & 55 & 53 & 28 & 44 & \\
\hline 4 & 2 & 5 & 6 & 6 & 4 & 6 & \\
\hline (y)pN stage & & & & & & & 0.09 \\
\hline 0 & 21 & 52 & 67 & 65 & 46 & 72 & \\
\hline 1 & 10 & 24 & 25 & 24 & 13 & 20 & \\
\hline 2 & 10 & 24 & 11 & 11 & 5 & 8 & \\
\hline
\end{tabular}


TABLE 1 continued

\begin{tabular}{|c|c|c|c|c|c|c|c|}
\hline \multirow{2}{*}{$\begin{array}{l}\text { Therapy regimen } \\
\text { Parameter }\end{array}$} & \multicolumn{2}{|c|}{ No neoadjuvant RCT } & \multicolumn{2}{|c|}{$\begin{array}{l}\text { Neoadjuvant RCT with } \\
\text { standard 5-FU }\end{array}$} & \multicolumn{2}{|c|}{$\begin{array}{l}\text { Neoadjuvant RCT with } \\
\text { 5-FU/oxaliplatin }\end{array}$} & \multirow[t]{2}{*}{$p^{*}$} \\
\hline & $\begin{array}{l}\text { No. of patients } \\
(n=41)\end{array}$ & $\%$ & $\begin{array}{l}\text { No. of patients } \\
(n=103)\end{array}$ & $\%$ & $\begin{array}{l}\text { No. of patients } \\
(n=64)\end{array}$ & $\%$ & \\
\hline (y)pUICC stage & & & & & & & 0.01 \\
\hline 0 & 0 & 0 & 8 & 8 & 9 & 14 & \\
\hline $\mathrm{I}$ & 5 & 12 & 24 & 23 & 22 & 34 & \\
\hline II & 16 & 39 & 32 & 31 & 13 & 20 & \\
\hline III & 19 & 46 & 30 & 29 & 15 & 23 & \\
\hline IV & 1 & 2 & 9 & 9 & 5 & 8 & \\
\hline \multicolumn{8}{|c|}{ Follow-up (145 months, last update 01/2010; median follow-up, 57 months) } \\
\hline \multicolumn{8}{|l|}{ Cancer recurrence } \\
\hline None & 31 & 68 & 78 & 75 & 49 & 76 & \\
\hline Local & 1 & 5 & 0 & 0 & 1 & 2 & \\
\hline Distant & 4 & 11 & 23 & 22 & 13 & 20 & \\
\hline Local and distant (synchronous) & 5 & 16 & 3 & 3 & 1 & 2 & \\
\hline Distant metastases & 9 & 22 & 26 & 25 & 14 & 21 & \\
\hline Hepar & 4 & 45 & 8 & 31 & 4 & 29 & \\
\hline Pulmo & 3 & 33 & 10 & 39 & 3 & 21 & \\
\hline Hepar and pulmo & 1 & 11 & 4 & 15 & 3 & 21 & \\
\hline Peritoneal and/or osseus & 1 & 11 & 4 & 15 & 4 & 29 & \\
\hline \multicolumn{8}{|l|}{ Follow-up time } \\
\hline Mean & 88 & & 50 & & 33 & & \\
\hline Range & $2-154$ & & $3-141$ & & $0-82$ & & \\
\hline Cancer-related death & 6 & 15 & 15 & 15 & 6 & 10 & \\
\hline \multicolumn{8}{|c|}{ TS expression in cUICC-II/-III rectal cancer cells } \\
\hline TS biopsy & & & & & & & 0.82 \\
\hline Mean & 3.85 & & 3.88 & & 4.02 & & \\
\hline Min - Max & $0-8$ & & $0-1$ & & $0-8$ & & \\
\hline TS tumor & & & & & & & 0.04 \\
\hline Mean & 6.03 & & 6.90 & & 7.28 & & \\
\hline Min - Max & $1-11$ & & $1-12$ & & $0-11$ & & \\
\hline TS genotype & & & & & & & 0.72 \\
\hline 22 & 4 & 24 & 17 & 20 & 17 & 33 & \\
\hline 24 & 0 & 0 & 1 & 1 & 0 & 0 & \\
\hline 32 & 9 & 53 & 41 & 49 & 24 & 46 & \\
\hline 33 & 4 & 24 & 24 & 29 & 11 & 21 & \\
\hline
\end{tabular}

* $P$ values from Chi-square test; for age difference from Kruskal-Wallis rank-sum test

\# In all cases TME was performed

uT, planned neoadjuvant treatment, and TS score in a Cox model from the staining of the biopsy) were assessed both in univariate analyses and a multivariate model. The TS scores of all patients with lymph node metastases after resection also were analyzed, including the following variables: (y)pT, applied neoadjuvant treatment and pretherapeutically measured TS score from tumor biopsy in a multivariate model. The global significance level was set to $\alpha=5 \%$. All statistical analyses were performed using the $R$ statistical computing environment version 2.11.0. ${ }^{41}$

\section{RESULTS}

\section{Patient Characteristics and Recurrence}

With respect to the primary tumor localization of rectal adenocarcinoma at staging (Table 1), 82 (39.4\%) tumors 
were localized in the lower third $(0-6 \mathrm{~cm}), 115(55.2 \%)$ tumors were localized in the middle third $(>6-12 \mathrm{~cm})$, and $14(6.7 \%)$ tumors were localized in the upper third $(>12-16 \mathrm{~cm})$ of the rectum. The surgical procedures consisted of $143(68.8 \%)$ low anterior resections, 61 (29.3\%) abdominoperineal resections, and 4 discontinuous resections (Hartmann's procedure) (1.4\%), all including TME. Focusing on the efficacy of neoadjuvant RCT in this study, the pretherapeutic cUICC staging and postoperative ypUICC tumor staging results are summarized in Table 1. By comparing pretherapeutic staging results and histopathological findings after surgery, T-level downsizing was found in 78 (46.7\%) patients, and UICC downstaging was achieved in 97 (58\%) patients. Median follow-up was 57 months. Cancer recurrence was observed in $41(23.2 \%)$ patients after neoadjuvant RCT and in 10 (24.3\%) patients who underwent adjuvant RCT. In patients with cancer recurrence, the predominant relapse was detected intrahepatic in $24(47 \%)$ cases of 51 patients with recurrent disease (Table 1).

\section{Pretherapeutic TS expression in Correlation with Tumor Regression Grading}

The current study did not reveal a correlation between pretreatment TS expression and RCT-induced histopathological tumor regression (TRG). TRG had no prognostic impact on DFS in this study, unless a complete tumor remission was achieved $(p=0.46 ; r=-0.16)$. Nevertheless, the long-term survival of patients with pCR after neoadjuvant RCT and extensive histopathological workup was excellent because no patient with $\mathrm{pCR}(n=16 ; 9.5 \%)$ exhibited cancer recurrence during the follow-up time.

\section{PRETHERAPEUTIC TS EXPRESSION AND PROGNOSIS}

TS expression in pretherapeutic biopsies showed a significant correlation with cancer-related death, demonstrating a benefit for patients with high TS expression ( $p=0.0406$; Fig. 3). The multivariate analyses (Table 2) of pretreatment TS score and other parameters available at the time of initial staging (age, uN, uT, and neoadjuvant treatment) revealed a significant correlation of low TS expression with a decrease in CSS $(p=0.01)$ and confirmed baseline TS expression levels as an independent prognostic marker.

\section{Prognostic Value of Intratumoral TS Expression in Resected Specimens}

In patients with histologically confirmed lymph node metastases, intratumoral TS expression of the resected tumor

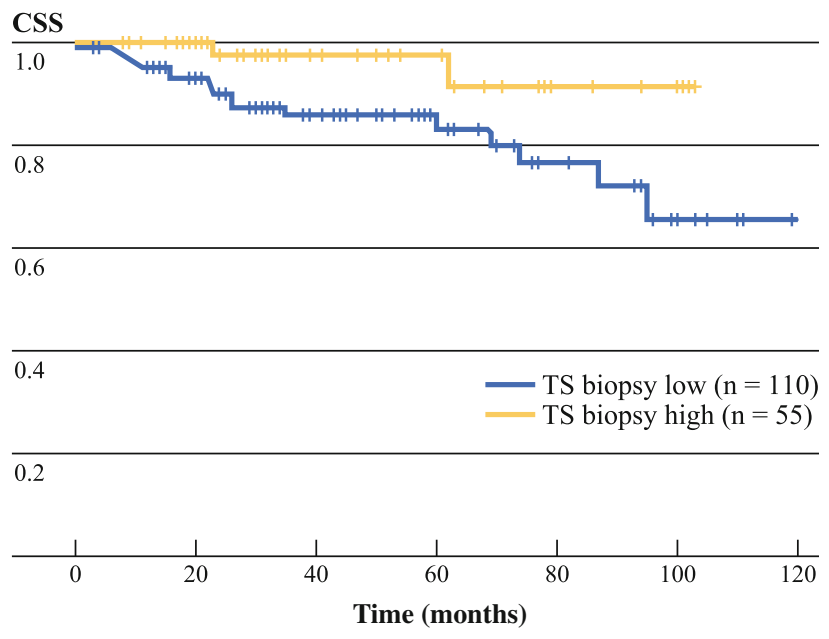

FIG. 3 Cox model for cancer-specific overall survival based on TS score in pretherapeutic biopsies $(p=0.0151)$. The cutoff in the Kaplan-Meier curves represents the median TS score and serves the purpose of visualization

specimens showed prognostic relevance. There was a significant decrease of DFS $(p=0.015)$ in patients with lymph node metastases $(n=74)$ and low TS expression (Fig. 4).

Included in a multivariate cox regression model (Table 2), TS expression in nodal-positive patients was significantly associated with a decreased DFS $(p=0.03)$.

\section{Findings in Patients with ypNO Status}

In nodal-negative patients, TS expression had no influence on DFS $(p=0.168)$. Furthermore, no significant differences in local and distant recurrences were observed within the three groups of patients.

\section{TS Genotype does Correlate with Intratumoral TS Protein Expression}

Genotypes of all patients with available blood samples $(n=152)$ for the TS 28-bp tandem repeat polymorphism revealed the following distribution: 39 patients $(25.7 \%)$ with $* 3 / * 3 ; 74$ patients $(48.7 \%)$ with $* 3 / * 2 ; 38$ patients $(25 \%)$ with $* 2 / * 2$; and 1 patient with the $* 2 / * 4$ allele. The correlation of the TS genotype $* 3 / * 3$ with TS protein expression revealed a trend of higher expression levels in biopsy specimens $(p=0.059)$ and tumor specimens $(p=0.229)$, but the difference was not statistically significant.

This result is consistent with the findings from previous analyses that revealed a coherency of several 28-bp repeats with higher intracellular TS expression. ${ }^{42}$ The statistical analysis of the TS genotype with local response, other clinicopathological findings (TRG, T-level downsizing, UICC downstaging, ypN and ypT status), DFS, and overall 
TABLE 2 Multivariate analyses of TS expression in pretreatment biopsies and in surgical specimens in correlation with disease-free survival and overall cancer-specific survival

\begin{tabular}{|c|c|c|c|c|c|c|c|c|c|}
\hline \multirow{3}{*}{$\begin{array}{l}\text { Patient } \\
\text { characteristics }\end{array}$} & \multirow{2}{*}{\multicolumn{2}{|c|}{$\frac{\text { TS expression }}{\text { Biopsy score }}$}} & \multirow{3}{*}{$\begin{array}{l}\text { Relation } \\
\text { TS } \\
p\end{array}$} & \multicolumn{3}{|c|}{ Disease-free survival } & \multicolumn{3}{|c|}{ Cancer-specific survival } \\
\hline & & & & \multirow{2}{*}{$\begin{array}{l}\text { Univariate } \\
\text { analysis } \\
p\end{array}$} & \multicolumn{2}{|l|}{$\begin{array}{l}\text { Multivariate } \\
\text { analysis }\end{array}$} & \multirow{2}{*}{$\begin{array}{l}\text { Univariate } \\
\text { analysis } \\
p\end{array}$} & \multicolumn{2}{|l|}{$\begin{array}{l}\text { Multivariate } \\
\text { analysis }\end{array}$} \\
\hline & $\begin{array}{l}\text { High }>4 \\
(N=110)\end{array}$ & $\begin{array}{l}\text { Low } \leq 4 \\
(N=55)\end{array}$ & & & $\begin{array}{l}\text { HR }(95 \% \\
\text { CI) }\end{array}$ & $p$ & & $\begin{array}{l}\text { HR }(95 \% \\
\text { CI })\end{array}$ & $p$ \\
\hline \multicolumn{10}{|c|}{ All patients - TS expression in pretreatment biopsy } \\
\hline Gender & & & 0.39 & 0.05 & $2.5(1.1-5.8)$ & $0.03 *$ & 0.4 & $1.5(0.5-4.2)$ & 0.44 \\
\hline Male $(\%)$ & 79 & 33 & & & & & & & \\
\hline Female $(\%)$ & 22 & 31 & & & & & & & \\
\hline Age $(y r)$ & & & 0.79 & 0.07 & $1(0.9-1)$ & 0.08 & 0.24 & $1(0.9-1)$ & 0.43 \\
\hline$\leq 63$ & 25 & 55 & & & & & & & \\
\hline$>63$ & 30 & 55 & & & & & & & \\
\hline $\mathrm{uN}$ & & & 0.44 & 0.55 & $1.2(0.6-2.4)$ & 0.68 & 0.15 & $2.3(0.7-8.3)$ & 0.19 \\
\hline- & 18 & 24 & & & & & & & \\
\hline+ & 37 & 86 & & & & & & & \\
\hline $\mathrm{uT}$ & & & 0.27 & 0.89 & $0.9(0.4-2.3)$ & 0.83 & 0.68 & $2.1(0.5-8.8)$ & 0.3 \\
\hline $1-2$ & 4 & 6 & & & & & & & \\
\hline $3-4$ & 51 & 104 & & & & & & & \\
\hline TRG & & & 1 & 0.34 & & & 0.35 & & \\
\hline $0,1,2,3 \mathrm{a}$ & 29 & 52 & - & - & - & - & - & - & - \\
\hline $3 b, 4$ & 18 & 39 & - & - & - & - & - & - & - \\
\hline \multicolumn{10}{|l|}{ Neoadjuvant therapy } \\
\hline No & 8 & 19 & & & & & & & \\
\hline $5-\mathrm{FU}$ & 25 & 54 & 0.78 & 0.43 & $1.1(0.5-2.6)$ & 0.81 & 0.24 & $0.9(0.3-3)$ & 0.9 \\
\hline $5-\mathrm{FU}+\mathrm{Ox}$ & 22 & 37 & 0.77 & 0.45 & $1.3(0.5-3.3)$ & 0.54 & 0.36 & $1.2(0.3-4.6)$ & 0.75 \\
\hline TS biopsy & & & & 0.14 & $0.9(0.8-1)$ & 0.15 & $0.015^{*}$ & $0.7(0.6-0.9)$ & $0.01 *$ \\
\hline \multirow[t]{3}{*}{ Patient characteristics } & \multicolumn{2}{|c|}{ TS expression } & Relation & \multicolumn{3}{|c|}{ Disease-free survival } & \multicolumn{3}{|c|}{ Cancer-specific survival } \\
\hline & \multicolumn{2}{|c|}{ Biopsy score } & TS & $\begin{array}{l}\text { Univariate } \\
\text { analysis }\end{array}$ & $\begin{array}{l}\text { Multivariate } \\
\text { analysis }\end{array}$ & & $\begin{array}{l}\text { Univariate } \\
\text { analysis }\end{array}$ & $\begin{array}{l}\text { Multivariate } \\
\text { analysis }\end{array}$ & \\
\hline & $\begin{array}{l}\text { High } \geq 7 \\
(N=31)\end{array}$ & $\begin{array}{l}\text { Low }<7 \\
(N=42)\end{array}$ & $p$ & $p$ & HR $(95 \% \mathrm{CI})$ & $p$ & $p$ & HR $(95 \% \mathrm{CI})$ & $p$ \\
\hline \multicolumn{10}{|c|}{ (y)pN + patients $-\mathrm{TS}$ expression in resection specimens } \\
\hline (y)pT & & & 0.53 & 0.37 & $1.2(0.7-2)$ & 0.58 & $0.04 *$ & $2.3(0.9-5.7)$ & 0.08 \\
\hline $1-2$ & 7 & 8 & & & & & & & \\
\hline $3-4$ & 24 & 34 & & & & & & & \\
\hline \multicolumn{10}{|l|}{ Neoadjuvant therapy } \\
\hline No & 7 & 13 & & & & & & & \\
\hline $5-\mathrm{FU}$ & 16 & 19 & 0.33 & 0.17 & $2.1(0.8-5.6)$ & 0.12 & $0.04 *$ & $4(1.1-15.3)$ & $0.04 *$ \\
\hline $5-\mathrm{FU}+\mathrm{Ox}$ & 8 & 10 & 0.21 & 0.39 & $1.5(0.5-4.8)$ & 0.47 & 0.21 & $2.7(0.5-14.4)$ & 0.25 \\
\hline TS biopsy & & & 0.18 & & & & & & \\
\hline Low $\leq 4$ & 5 & 24 & & & & & & & \\
\hline High $>4$ & 11 & 17 & & & & & & & \\
\hline TS tumor & & & & $0.04 *$ & $0.9(0.8-1)$ & $0.03^{*}$ & 0.35 & $0.9(0.8-1.1)$ & 0.55 \\
\hline
\end{tabular}

* Significant results 


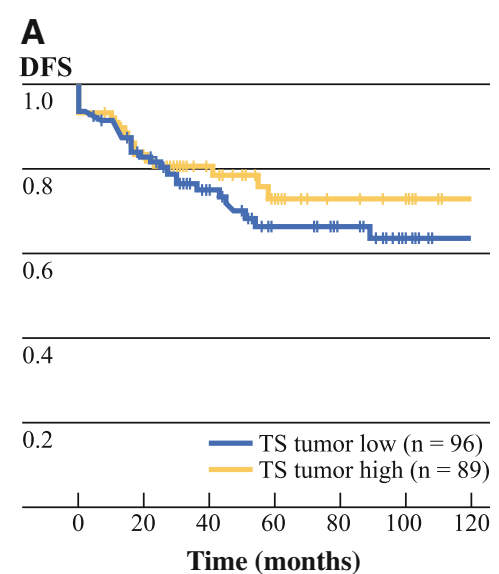

B

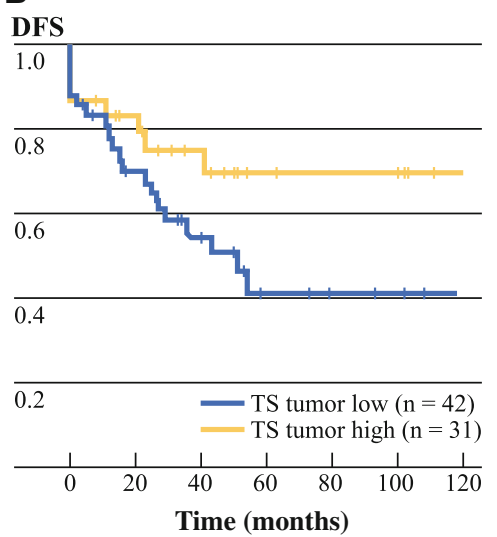

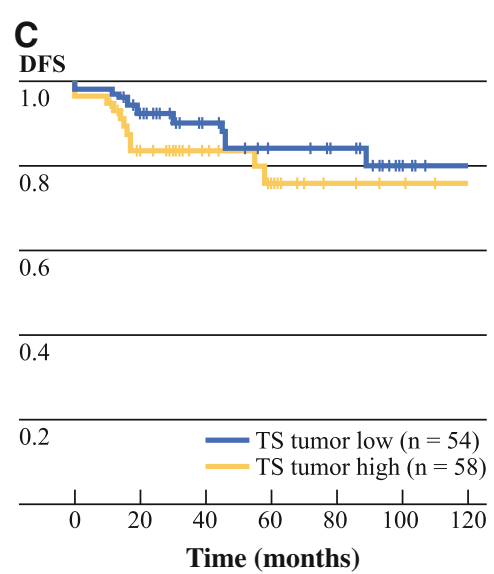

FIG. 4 Cox model for disease-free survival based on TS score in resection specimens. The cutoff in the Kaplan-Meier curves represents the median TS score and serves the purpose of visualisation. a Trend of better disease-free survival for patients with high TS expression in the complete patient cohort $(p=0.213)$. b Patients

survival did not reveal any association in the analyzed patient cohort that could currently be used for a specific risk assessment.

\section{DISCUSSION}

Our analysis is the largest study so far to characterize TS expression from pretherapeutic biopsies and the corresponding surgical specimens from patients with rectal cancer treated in multimodal concepts. ${ }^{22}$ Although previous analyses of smaller patient cohorts reported high TS expression as a negative prognostic biomarker, recent data, in accordance with our present findings, have shown a benefit for patients with high intratumoral TS expression. . $^{23,25,43-46}$

Within previous studies, Jakob et al. ${ }^{43}$ evaluated TS expression levels in 40 patients and found a correlation between low TS expression and TRG. In patients with RCTinduced pCR (TRG-4), we observed an excellent clinical course without any cancer recurrence during the follow-up period. Moreover, tumor regression grades between 1 and 3 did not predict long-term survival. In further analyses, based on a very small patient cohort, Jakob et al. postulated that high TS levels indicated unfavorable prognosis in patients with cancer recurrence $(n=9)$ without RCT-induced UICC downstaging. This hypothesis was supported by several other studies as reviewed by Kuremsky et al. ${ }^{22}$; however, they primarily investigated the correlation with local response parameters, out of the context of DFS and overall survival. Other reasons for opposite conclusions of previous studies might be rooted in a lack of differentiation between colon and rectal cancer, limited analyses with results derived from small subgroups, and finally different methodological approaches. with histopathologically proven lymph node metastases and low TS expression show an increased disease-free survival $(p=0.0406)$. c Patients with nodal negative show the most favorable disease-free survival during follow-up independent of TS expression ( $p=$ $0.168)$

We evaluated TS protein level by IHC, because it can be easily implemented into clinical routine. Another approach to investigate the impact of TS was the pharmacogenetic analysis of gene polymorphisms. ${ }^{47}$ A comparative analysis of quantitative TS protein expression detected by IHC and genotype also confirmed the coherence of the TS polymorphism with intratumoral expression activity. Aside from the analyses of single nucleotide polymorphisms, a 28-bp repeat within the TS gene seems to be of interest. ${ }^{42,48,49}$ A correlation between the number of 28-bp repeats and gene and protein expression efficacy has been repeatedly found and confirmed by our investigations. ${ }^{50,51}$

Low TS expression from pretherapeutic biopsies showed prognostic value with respect to impaired CSS. Based on these findings, one could conjecture a benefit from the intensification of neoadjuvant RCT protocols, especially for patients who do not sufficiently respond to preoperative RCT with 5-FU monotherapy. Indeed, a better outcome for patients with low TS expression was observed under the intensified treatment with 5-FU and oxaliplatin, although these data originated from a subgroup analysis. A prospective validation of this observation in a large patient cohort would be crucial for implementing the pretherapeutic TS expression level assessment into clinical practice. Within a prospectively randomized clinical trial, stratification of patients for the neoadjuvant RCT regimen as well as for the adjuvant treatment according to TS expression and further markers for the patients' individual risk would be the next step toward individualized therapy.

\section{CONCLUSIONS}

This study demonstrates the prognostic value of TS in locally advanced rectal cancer treated with multimodal 
5-FU-based RCT. The analyses show an unfavorable prognosis in patients with low intratumoral TS expression. Standardized IHC staining could easily integrate TS analysis into routine staging procedures and could be used for stratification of adjuvant therapy. Particularly, patients with persistent positive lymph node status and low TS expression in the resected specimen are at a higher risk for cancer recurrence. These patients might benefit from an intensified treatment regime and potential higher rates of therapyassociated toxicity might be justified. Prospective validation in future clinical trials is crucial for legitimating the treatment stratification based on the TS expression level.

ACKNOWLEDGMENT The authors thank Birgit Jüneman for her excellent technical assistance and providing outstanding slides for immunohistochemical staining. We appreciate the participation of all patients in this study in clinical trials. We thank Arne Lornsen for genotyping assistance. We also thank the study team for oncological trials (Elke Stauffer, Johanna Kreutzer, Beate Michels, Claudia Heuermann, and Recca Talaulicar) for patient monitoring and data management. Special thanks are directed to Penelope Bradbury, MD, (Kingston, Ontario, CA) for critical comments and reading of the manuscript. This study was funded by the German Research Foundation (DFG) clinical research group 179.

OPEN ACCESS This article is distributed under the terms of the Creative Commons Attribution Noncommercial License which permits any noncommercial use, distribution, and reproduction in any medium, provided the original author(s) and source are credited.

\section{REFERENCES}

1. Rödel C. Radiotherapy: preoperative chemoradiotherapy for rectal cancer. Nat Rev Clin Oncol. 2010;7:129-30.

2. Heald RJ, Husband EM, Ryall RD. The mesorectum in rectal cancer surgery-the clue to pelvic recurrence? Br J Surg. 1982; 69:613-6.

3. MacFarlane JK, Ryall RD, Heald RJ. Mesorectal excision for rectal cancer. Lancet. 1993;341:457-60.

4. Bosset JF, Collette L, Calais G, et al. Chemotherapy with preoperative radiotherapy in rectal cancer. $N$ Engl J Med. 2006; 355:1114-23.

5. Gerard JP, Conroy T, Bonnetain F, et al. Preoperative radiotherapy with or without concurrent fluorouracil and leucovorin in T3-4 rectal cancers: results of FFCD 9203. J Clin Oncol. 2006;24:4620-5.

6. Rödel C, Martus P, Papadoupolos T, et al. Prognostic significance of tumor regression after preoperative chemoradiotherapy for rectal cancer. J Clin Oncol. 2005;23:8688-96.

7. Sauer R, Becker H, Hohenberger W, et al. Preoperative versus postoperative chemoradiotherapy for rectal cancer. $N$ Engl J Med. 2004;351:1731-40.

8. Schmiegel W, Reinacher-Schick A, Arnold D, et al. [Update S3-guideline "colorectal cancer" 2008]. Z Gastroenterol. 2008; 46:799-840.

9. Sprenger T, Rothe H, Homayounfar K, Beissbarth T, Ghadimi BM, Becker H, Liersch T. Preoperative chemoradiotherapy does not necessarily reduce lymph node retrieval in rectal cancer specimens: results from a prospective evaluation with extensive pathological work-up. J Gastrointest Surg. 2010;14:96-103.
10. Kaminsky-Forrett MC, Conroy T, Luporsi E, et al. Prognostic implications of downstaging following preoperative radiation therapy for operable T3-T4 rectal cancer. Int J Radiat Oncol Biol Phys. 1998;42:935-41.

11. Sprenger T, Rothe H, Jung K, et al. (2010) Stage II/III rectal cancer with intermediate response to preoperative radiochemotherapy: do we have indications for individual risk stratification? World J Surg Oncol. 8:27.

12. Koopman M, Venderbosch S, Nagtegaal ID, van Krieken JH, Punt CJ. A review on the use of molecular markers of cytotoxic therapy for colorectal cancer, what have we learned? Eur J Cancer. 2009;45:1935-49.

13. Bujko K, Michalski W, Kepka L, et al. Association between pathologic response in metastatic lymph nodes after preoperative chemoradiotherapy and risk of distant metastases in rectal cancer: an analysis of outcomes in a randomized trial. Int J Radiat Oncol Biol Phys. 2007;67:369-77.

14. Bujko K, Glynne-Jones R, Bujko M. Does adjuvant fluoropyrimidine-based chemotherapy provide a benefit for patients with resected rectal cancer who have already received neoadjuvant radiochemotherapy? A systematic review of randomised trials. Ann Oncol. 2010;21(9):1743-50.

15. Monga DK, O'Connell MJ. Surgical adjuvant therapy for colorectal cancer: current approaches and future directions. Ann Surg Oncol. 2006;13:1021-34.

16. Rodel C, Sauer R. Integration of novel agents into combinedmodality treatment for rectal cancer patients. Strahlenther Onkol. 2007;183:227-35.

17. Meyers M, Wagner MW, Hwang HS, Kinsella TJ, Boothmann DA. Role of the hMLH1 DNA mismatch repair protein in fluoropyrimidine-mediated cell death and cell cycle responses. Cancer Res. 2001;61:5193-201.

18. Minsky BD, Cohen AM, Kemeny N, et al. Enhancement of radiation-induced downstaging of rectal cancer by fluorouracil and high-dose leucovorin chemotherapy. J Clin Oncol. 1992; 10:79-84.

19. Heidelberger C, Chaudhuri NK, Danneberg P, et al. Fluorinated pyrimidines, a new class of tumour-inhibitory compounds. Nature. 1957;179:663-6.

20. McGinn CJ, Pestalozzi BC, Drake JC, et al. Cell cycle regulation of the G0/G1 transition in 5-fluorouracil-sensitive and -resistant human colon cancer cell lines. Cancer J. 2000;6:234-42.

21. Popat S, Matakidou A, Houlston RS. Thymidylate synthase expression and prognosis in colorectal cancer: a systematic review and meta-analysis. J Clin Oncol. 2004;22:529-36.

22. Kuremsky JG, Tepper JE, McLeod HL. Biomarkers for response to neoadjuvant chemoradiation for rectal cancer. Int $J$ Radiat Oncol Biol Phys. 2009;74:673-88.

23. Kikuchi M, Mikami T, Sato T, et al. High Ki67, Bax, and thymidylate synthase expression well correlates with response to chemoradiation therapy in locally advanced rectal cancers: proposal of a logistic model for prediction. Br J Cancer. 2009;101: 116-23.

24. Jakob C, Liersch T, Meyer W, Becker H, Baretton GB, Aust DE. Predictive value of Ki67 and p53 in locally advanced rectal cancer: correlation with thymidylate synthase and histopathological tumor regression after neoadjuvant 5-FU-based chemoradiotherapy. World J Gastroenterol. 2008;14:1060-6.

25. Negri FV, Campanini N, Camisa R, et al. Biological predictive factors in rectal cancer treated with preoperative radiotherapy or radiochemotherapy. Br J Cancer. 2008;98:143-7.

26. Spindler KL, Nielsen JN, Lindebjerg J, Jakobsen A. Germline polymorphisms may act as predictors of response to preoperative chemoradiation in locally advanced T3 rectal tumors. Dis Colon Rectum. 2007;50:1363-9. 
27. Stoehlmacher J, Goekkurt E, Mogck U, et al. Thymidylate synthase genotypes and tumour regression in stage II/III rectal cancer patients after neoadjuvant fluorouracil-based chemoradiation. Cancer Lett. 2008;272:221-5.

28. Liersch $\mathrm{T}$, Langer $\mathrm{C}$, Jakob $\mathrm{C}$, et al. [Preoperative diagnostic procedures in locally advanced rectal carcinoma $(>$ or $=\mathrm{T} 3$ or $\mathrm{N}+$ ). What does endoluminal ultrasound achieve at staging and restaging (after neoadjuvant radiochemotherapy) in contrast to computed tomography?]. Chirurg. 2003;74:224-34.

29. Oken MM, Creech RH, Tormey DC, Horton J, Davis TE, McFadden ET, Carbone PP. Toxicity and response criteria of the Eastern Cooperative Oncology Group. Am J Clin Oncol. 1982;5: 649-55.

30. Chavaudra J. [Last ICRU recommendations for the prescription, recording and reporting of external bean therapy]. Cancer Radiother. 1998;2:607-14.

31. Vorwerk H, Liersch T, Rothe H, Ghadimi BM, Christiansen H, Hess CF, Herrmann RM. Gold markers for tumor localization and target volume delineation in radiotherapy for rectal cancer. Strahlenther Onkol. 2009;185:127-33.

32. Brierley JD, Greene FL, Sobin LH, Wittekind C. The "y" symbol: an important classification tool for neoadjuvant cancer treatment. Cancer. 2006;106:2526-7.

33. Sobin LH. TNM, sixth edition: new developments in general concepts and rules. Semin Surg Oncol. 2003;21:19-22.

34. Quirke P, Steele R, Monson J, et al. Effect of the plane of surgery achieved on local recurrence in patients with operable rectal cancer: a prospective study using data from the MRC CR07 and NCIC-CTG CO16 randomised clinical trial. Lancet. 2009;373: 821-8.

35. Nagtegaal ID, van de Velde CJ, van der Worp E, Kapiteijn E, Quirke P, van Krieken JH. Macroscopic evaluation of rectal cancer resection specimen: clinical significance of the pathologist in quality control. J Clin Oncol. 2002;20:1729-34.

36. Dworak O, Keilholz L, Hoffmann A. Pathological features of rectal cancer after preoperative radiochemotherapy. Int $J$ Colorectal Dis. 1997;12:19-23.

37. Liersch T, Langer C, Ghadimi BM, et al. Lymph node status and TS gene expression are prognostic markers in stage II/III rectal cancer after neoadjuvant fluorouracil-based chemoradiotherapy. $J$ Clin Oncol. 2006;24:4062-8.

38. McShane LM, Altman DG, Sauerbrei W, Taube SE, Gion M, Clark GM. REporting recommendations for tumour MARKer prognostic studies (REMARK). Br J Cancer. 2005;93:387-91.

39. Remmele W, Stegner HE. Recommendation for uniform definition of an immunoreactive score (IRS) for immunohistochemical estrogen receptor detection (ER-ICA) in breast cancer tissue. Pathologe. 1987;8:138-40.
40. Dotor E, Cuatrecases M, Martinez-Iniesta M, et al. Tumor thymidylate synthase 1494del6 genotype as a prognostic factor in colorectal cancer patients receiving fluorouracil-based adjuvant treatment. J Clin Oncol. 2006;24:1603-11.

41. R Development Core Team: R: Language and environment for statistical computing. http://www.r-project.org/ 2010.

42. Paez D, Pare L, Altes A, et al. Thymidylate synthase germline polymorphisms in rectal cancer patients treated with neoadjuvant chemoradiotherapy based on 5-fluorouracil. J Cancer Res Clin Oncol. 2010;136:1681-9.

43. Jakob C, Aust DE, Meyer W, et al. Thymidylate synthase, thymidine phosphorylase, dihydropyrimidine dehydrogenase expression, and histological tumour regression after 5-FU-based neoadjuvant chemoradiotherapy in rectal cancer. J Pathol. 2004; 204:562-8.

44. Okonkwo A, Musunuri S, Talamonti M, Benson A III, Small W Jr, Styker SJ, Rao MS. Molecular markers and prediction of response to chemoradiation in rectal cancer. Oncol Rep. 2001;8: 497-500.

45. Johnston PG, Fisher ER, Rockette HE, et al. The role of thymidylate synthase expression in prognosis and outcome of adjuvant chemotherapy in patients with rectal cancer. J Clin Oncol. 1994; 12:2640-7.

46. Karlberg M, Ohrling K, Edler D, Hallström M, Ullén H, Raynhammer P. Prognostic and predictive value of thymidylate synthase expression in primary colorectal cancer. Anticancer Res. 30:645-51.

47. Gosens MJ, Moerland E, Lemmens VP, Rutten HT, Tan-Go I, van de Brule AJ. Thymidylate synthase genotyping is more predictive for therapy response than immunohistochemistry in patients with colon cancer. Int J Cancer. 2008;123:1941-9.

48. Shahrokni A, Rajebi MR, Saif MW. Toxicity and efficacy of 5-fluorouracil and capecitabine in a patient with TYMS gene polymorphism: a challenge or a dilemma? Clin Colorectal Cancer. 2009;8:231-4.

49. Popat S, Wort R, Houlston RS. Relationship between thymidylate synthase (TS) genotype and TS expression: a tissue microarray analysis of colorectal cancers. Int J Surg Pathol. 2005;13:127-33.

50. Horie N, Aiba H, Oguro K, Hojo H, Takeishi K. Functional analysis and DNA polymorphism of the tandemly repeated sequences in the $5^{\prime}$-terminal regulatory region of the human gene for thymidylate synthase. Cell Struct Funct. 1995;20:191-7.

51. Kawakami K, Omura K, Kanehira E, Watanabe Y. Polymorphic tandem repeats in the thymidylate synthase gene is associated with its protein expression in human gastrointestinal cancers. Anticancer Res. 1999;19:3249-52. 